\title{
Dialkoxynaphthalene as an electron-rich unit for high-performance polymer solar cells with large open circuit voltages
}

Hao Qin, ${ }^{a, b}$ Dongdong Cai, ${ }^{a}$ Meng Wang, ${ }^{a, b}$ Yunlong Ma, ${ }^{\text {Z } Z h i g a n g ~ Y i n, ~},{ }^{\mathrm{a}, \mathrm{b}}$ Changquan Tang, ${ }^{\mathrm{a}}$ Shan-Ci Chen ${ }^{a}$ and Qingdong Zheng ${ }^{\mathrm{a}, *}$

${ }^{a}$ State Key Laboratory of Structural Chemistry, Fujian Institute of Research on the Structure of Matter, Chinese Academy of Sciences, Fuzhou, 350002, P. R. China. E-mail:

qingdongzheng@fjirsm.ac.cn

${ }^{\mathrm{b}}$ University of Chinese Academy of Sciences, Beijing 100049, P. R. China

*To whom correspondence should be addressed.

\begin{abstract}
Dialkoxynaphthalene is a simple aromatic building block, which can be synthesized easily in a large scale. In this work, two dialkoxynaphthalene derivatives were copolymerized with electron-withdrawing benzothiadiazole (BT) derivatives to afford three donor-acceptor copolymers, PNDTBT, PNT2FTBT and PN2FTBT. The three copolymers have diverse bandgaps ranged from 1.73 to $1.86 \mathrm{eV}$, and deep HOMO energy levels up to $-5.61 \mathrm{eV}$. Thermogravimetric analysis and electrochemical measurements show that these copolymers have good thermal and environment stability. The hole mobilities of these copolymers were investigated using the space charge limited current (SCLC) method as well as the organic field effect transistor (OFET) method. Polymer solar cells based on PNDTBT exhibit the best photovoltaic performance with a power conversion efficiency of $6.24 \%$ and a $V_{\text {oc }}$ of $0.94 \mathrm{~V}$, much better than those of previously reported copolymers based on dialkoxynaphthalene.
\end{abstract}

Keywords: Conjugated polymers; Dialkoxynaphthalene; Polymer solar cells 


\section{Introduction}

Polymer solar cells (PSCs) have received tremendous attention in the past decade because of their unique properties such as light-weight, tunable photochemical properties, mechanical flexibility and easy processing for large-area devices [1-7]. In particular, polymer/fullerene-based bulk-heterojunction (BHJ) solar cells have been intensively investigated, and their power conversion efficiencies (PCEs) have been successfully pushed past $10 \%$ [8-11]. Further improvements in the device efficiency and stability as well as the processing cost are expected along with development of new active materials and novel device architectures. In terms of the active materials, fullerene derivatives are the most competitive acceptor materials [12-15]. To achieve an appropriate energy level match between the donor materials and fullerene derivatives in the BHJ solar cells, efforts should be focused on the design and synthesis of novel donor materials with optimal bandgaps and suitable frontier molecular orbital (FMO) energy levels. Moreover, processing cost is also an important issue has to be addressed before the commercialization of PSCs in addition to the high efficiency and long lifetime. Low processing cost could be realized by using inexpensive materials, less processing steps and mild processing conditions. Polymers based on simple building blocks usually can be synthesized in large scale with low cost and high purity, which will subsequently help to reduce the total processing cost of PSCs.

Both dialkoxylphenylene and dialkoxynaphthalene are simple aromatic building blocks, which can be synthesized easily in large scale. Thus the resulting copolymers based on them can be prepared much easier compared to many other copolymers with complicated structures $[3,6, \quad 9] . \quad$ In fact, dialkoxylphenylene-based polymers, such as poly[2-methoxy-5-(2-ethylhexyloxy)-1,4-phenylenevinylene] (MEH-PPV) and poly[2-methoxy-5-(3,7-dimethyloctyloxy)-1,4-phenylenevinylene] (MDMO-PPV) dominated the photovoltaic research field in the 1990s, and the devices based on them exhibited PCEs of $\sim 3 \%$ [16-18]. It is difficult to further improve the PCEs of these polymers due to their large bandgaps, low mobility and inappropriate FMO energy levels. A useful strategy is to design alternating donor-acceptor (D-A) copolymers, where the electron donor unit may provide a deeper HOMO level and the electron acceptor unit is used to tune the electronic band gap of 
the polymers. For example, a series of copolymers based on dialkoxyphenylene and benzothiadiazole units were developed for PSCs with remarkable PCEs exceed 9\%.[19] Compared to benzene derivatives, naphthalene counterparts have similar simple chemical structures but extended $\pi$-conjugation system which is helpful for improved light-harvesting and carrier transportation [20]. Surprisingly, dialkoxylnaphthalene-based copolymers are seldom explored, and their photovoltaic performances are inferior to those of many D-A copolymers [21-24]. For example, the first alternating copolymer based on bithiophene and didecyloxynaphthalene was demonstrated to exhibit an open circuit voltage $\left(V_{\text {oc }}\right)$ of $0.83 \mathrm{~V}$ and a power conversion efficiency (PCE) of $1.3 \%$ when blended with [6,6]-phenyl-C61-butyric acid methyl ester [21]. Later on, Kwon et al. developed two alternating copolymers based on the didecyloxynaphthalene and 2,3-bis-(thiophene-2-yl)acrylronitrile. When the two copolymers were used for polymer solar cells, a maximum PCE of $2.9 \%$ with a $V_{\text {oc }}$ of $0.88 \mathrm{~V}$ was achieved [24]. The relatively inferior photovoltaic performance of the dialkoxylnaphthalene-based copolymers could be attributed to the inappropriate selection of the acceptor unit, which leads to copolymers with low molecular weights or improper FMO energy levels. As we know, benzothiadiazole derivatives have been frequently used as excellent acceptor units in the past decade due to their tunable electron-withdrawing ability as well as solubility [6, 25-28]. For example, by the incorporation of fluorine atom into the benzothiadiazole unit, the resulting copolymers exhibited lowered the lowest unoccupied molecular orbital (LUMO) and highest occupied molecular orbital (HOMO) energy levels. By contrast, the introduction of dialkoxyl groups will lead to polymers with increased solubility but elevated LUMO and HOMO energy levels. In this context, three dialkoxynaphthalene and substituted benzothiadiazole-based copolymers, namely, poly[2,2'-(1,5-bis((2-decyltetradecyl)oxy)naphthalene-2,6-diyl) dithiophene-alt-5,6-bis(hexyloxy)-4,7-di(thiophen-2-yl)benzo[c][1,2,5]thiadiazole] (PNDTBT), poly[2,2'-(1,5-bis((2-decyltetradecyl) oxy)naphthalene-2,6-diyl)dithiophenealt-5,6-difluoro-4,7-di(thiophen-2-yl)benzo[c][1,2,5]thiadiazole] (PNT2FTBT) and poly[1,5-bis((2-decyltetradecyl)oxy)naphthalene-alt-5,6-difluoro-4,7-di(thiophen-2-yl)benzo[ c][1,2,5] thiadiazole] (PN2FTBT) were designed, synthesized and characterized. When they were used for the fabrication of PSCs, PNDTBT-based devices achieved the highest PCE of 
$6.24 \%$ with a high $V_{\mathrm{oc}}$ of $0.94 \mathrm{~V}$, a short-circuit density $\left(J_{\mathrm{sc}}\right)$ of $10.76 \mathrm{~mA} / \mathrm{cm}^{2}$, and a fill factor (FF) of $61.8 \%$, which are much better than those based on other dialkoxynaphthalene-based copolymers [21-24]. For the copolymers based on the fluorinated benzothiadiazole (PNT2FTBT), a high PCE of 5.09\% was also achieved with a $V_{\mathrm{oc}}$ of $0.82 \mathrm{~V}$. Furthermore, the hole transporting properties of the copolymers were investigated and discussed in regard to their structure/property relationships.

\section{Experimental}

Reagents were purchased from Aladdin, Aldrich and used without further purification unless otherwise noted. [6,6]-Phenyl C71-butyric acid methyl ester $\left(\mathrm{PC}_{71} \mathrm{BM}\right)$ was purchased from American Dye Source Inc. 2,6-Dibromonaphthalene-1,5-diol was purchased from TCI (China). THF was purified by fractional distillation over sodium/benzophenone. Other solvents were dried over molecular sieves. 5,6-Bis(hexyloxy)-4,7-bis(5-(trimethylstannyl) thiophen-2-yl)benzo[c][1,2,5]thiadiazle (M3) and 5,6-difluoro-4,7-bis(5-(trimethylstannyl) thiophen-2-yl)benzo[c][1,2,5]thiadiazole (M4) were synthesized according to the literature methods $[19,29,30]$. Column chromatography was carried out with silica gel (200-300 mesh). The synthesis of the conjugated polyelectrolyte (PIFB) has been discribed by us previously [31].

\subsection{Synthesis}

\subsubsection{2,6-Dibromo-1,5-bis((2-decyltetradecyl)oxy)naphthalene (M1)}

In a $100 \mathrm{~mL}$ round-bottom flask, compound $1(0.63 \mathrm{~g}, 1.98 \mathrm{mmol})$ and $\mathrm{NaOH}(0.80 \mathrm{~g}, 20$ mmol) were dissolved in $30 \mathrm{~mL}$ of dimethyl sulfoxide (DMSO). After flushed with $\mathrm{N}_{2}$ for 30 min, 11-(bromomethyl)tricosane $(2.50 \mathrm{~g}, 5.98 \mathrm{mmol})$ was added dropwise into the solution. The mixture was heated to $85{ }^{\circ} \mathrm{C}$ with stirring for 3 days. After cooling to room temperature, the mixture was poured into ice water and extracted with ethyl acetate twice, organic phase was washed with water, brine, dried over $\mathrm{MgSO}_{4}$ and filtered. Solvent was evaporated under reduced pressure and purified by column chromatography on silica gel using petroleum ether as eluent. After crystallized in methanol, compound M1 was obtained with a white solid (1.12 g, 56.5\%). ${ }^{1} \mathrm{H}$ NMR $\left(400 \mathrm{MHz}, \mathrm{CDCl}_{3}, \delta\right): 7.76(\mathrm{~d}, J=8.8 \mathrm{~Hz}, 2 \mathrm{H}), 7.63(\mathrm{~d}, J=9.2 \mathrm{~Hz}, 2 \mathrm{H})$, $3.95(\mathrm{~d}, J=5.6 \mathrm{~Hz}, 4 \mathrm{H}), 1.97(\mathrm{~m}, 2 \mathrm{H}), 1.63-1.28(\mathrm{~m}, 80 \mathrm{H}), 0.89(\mathrm{~m}, 12 \mathrm{H}) .{ }^{13} \mathrm{C}$ NMR $(400$ 
$\left.\mathrm{MHz}, \mathrm{CDCl}_{3}, \delta\right): 152.96,130.96,130.06,119.19,113.69,77.32,76.94,76.69,39.26,36.04$, 31.96, 31.15, 30.09, 29.60, 29.49, 29.39, 27.87, 27.01, 22.61, 14.12. HRMS (MALDI-DHB) $\mathrm{m} / \mathrm{z}:[\mathrm{M}+\mathrm{H}]^{+}$calcd for $\mathrm{C}_{58} \mathrm{H}_{102} \mathrm{O}_{2} \mathrm{Br}_{2}$ : 988.6241; found: 988.6231 .

\subsubsection{2,2'-(1,5-Bis((2-decyltetradecyl)oxy)naphthalene-2,6-diyl)dithiophene (2)}

Compound M1 (0.60 g, $0.61 \mathrm{mmol})$ and tributyl(thiophen-2-yl)stannane (0.68 g $1.83 \mathrm{mmol})$ were dissolved in DMF/toluene mixed solvents (3/1, $40 \mathrm{~mL}) . \mathrm{Pd}\left(\mathrm{PPh}_{3}\right)_{4}(25 \mathrm{mg}, 0.02 \mathrm{mmol})$ was added into the solution under $\mathrm{N}_{2}$ atmosphere. After flushed with $\mathrm{N}_{2}$ for $30 \mathrm{~min}$, the solution was heated to $90{ }^{\circ} \mathrm{C}$ for 24 hours. After cooling to room temperature, the mixture was poured into ice water and extracted with ethyl acetate twice, organic phase was separated and washed with water, brine, dried over $\mathrm{MgSO}_{4}$ and filtered. Solvent was evaporated under reduced pressure, the residue was purified by column chromatography on silica gel (petroleum ether) to afford a white solid $(0.58 \mathrm{~g}, 92.3 \%) .{ }^{1} \mathrm{H} \mathrm{NMR}\left(400 \mathrm{MHz}, \mathrm{CDCl}_{3}, \delta\right): 7.96$ $(\mathrm{d}, J=8.8 \mathrm{~Hz}, 2 \mathrm{H}), 7.77(\mathrm{~d}, J=8.8 \mathrm{~Hz}, 2 \mathrm{H}), 7.59(\mathrm{~d}, J=3.2 \mathrm{~Hz}, 2 \mathrm{H}), 7.41(\mathrm{~d}, J=4.4 \mathrm{~Hz}, 2 \mathrm{H})$, $7.16(\mathrm{t}, J=4.4 \mathrm{~Hz}, 2 \mathrm{H}), 3.75(\mathrm{~d}, J=6.0 \mathrm{~Hz}, 4 \mathrm{H}), 2.02(\mathrm{~m}, 2 \mathrm{H}), 1.29-1.48(\mathrm{~m}, 80 \mathrm{H}), 0.91(\mathrm{~m}$, 12H). ${ }^{13} \mathrm{C}$ NMR (100 MHz, $\left.\mathrm{CDCl}_{3}, \delta\right): 151.86,139.40,129.65,127.15,126.88,125.97$, $123.58,118.76,77.33,77.02,76.70,39.25,31.96,31.20,30.10,29.71,29.35,26.84,22.63$, 14.07. HRMS (MALDI-DHB) $\mathrm{m} / \mathrm{z}:[\mathrm{M}+\mathrm{H}]^{+}$calcd for $\mathrm{C}_{66} \mathrm{H}_{108} \mathrm{O}_{2} \mathrm{~S}_{2}$ : 996.7785 , found: 996.7793.

\subsubsection{5,5'-(1,5-Bis((2-decyltetradecyl)oxy)naphthalene-2,6-diyl)bis(2-bromothiophene) (M2)}

A mixture of compound $2(0.58 \mathrm{~g}, 0.57 \mathrm{mmol}), 30 \mathrm{~mL}$ of methylene chloride and $10 \mathrm{~mL}$ of acetic acid was cooled to $0{ }^{\circ} \mathrm{C}$. NBS $(0.11 \mathrm{~g}, 0.6 \mathrm{mmol})$ was added under $\mathrm{N}_{2}$ atmosphere. The solution was then warmed up to room temperature and stirred for 3 hours. The mixture was poured into ice water and extracted with methylene chloride twice, organic phase was washed by water, brine and dried over $\mathrm{MgSO}_{4}$, the solvent was evaporated to give crude product.

High-purity product was obtained after crystallization from methanol $(0.56 \mathrm{~g}, 83.2 \%) .{ }^{1} \mathrm{H}$ $\operatorname{NMR}\left(400 \mathrm{MHz}, \mathrm{CDCl}_{3}, \delta\right): 7.91(\mathrm{~d}, J=8.8 \mathrm{~Hz}, 2 \mathrm{H}), 7.70(\mathrm{~d}, J=8.8 \mathrm{~Hz}, 2 \mathrm{H}), 7.32(\mathrm{~d}, J=$ $4.4 \mathrm{~Hz}, 2 \mathrm{H}), 7.10(\mathrm{t}, J=4.4 \mathrm{~Hz}, 2 \mathrm{H}), 3.75(\mathrm{~d}, J=6 \mathrm{~Hz}, 4 \mathrm{H}), 2.06(\mathrm{~m}, 2 \mathrm{H}), 1.29-1.48(\mathrm{~m}$, $80 \mathrm{H}), 0.91(\mathrm{~m}, 12 \mathrm{H}) .{ }^{13} \mathrm{C} \mathrm{NMR}\left(100 \mathrm{MHz}, \mathrm{CDCl}_{3}, \delta\right): 151.63,140.85,129.65,126.15,123.14$, $119.01,113.49,77.83,77.33,77.01,76.69,39.15,31.96,31.20,30.06,29.70,29.35,26.89$, 22.71. HRMS (MALDI-DHB) m/z: $[\mathrm{M}+\mathrm{H}]^{+}$calcd for $\mathrm{C}_{66} \mathrm{H}_{106} \mathrm{O}_{2} \mathrm{Br}_{2} \mathrm{~S}_{2}$ : 1152.6055; found: 
1152.5996 .

\subsubsection{PNDTBT}

M2 $(0.232 \mathrm{~g}, 0.2 \mathrm{mmol}), \mathbf{M 3}(0.135 \mathrm{~g}, 0.2 \mathrm{mmol})$ were dissolved in $20 \mathrm{~mL}$ of toluene. The solution was degassed with $\mathrm{N}_{2}$ for one hour, and then $\mathrm{Pd}\left(\mathrm{PPh}_{3}\right)_{4}(20 \mathrm{mg}, 0.016 \mathrm{mmol})$ was added. The mixture was heated to reflux in $\mathrm{N}_{2}$ atmosphere for three days. 2-tributyl(thiophen-2-yl)stannane $(0.05 \mathrm{~mL})$ was added and the mixture was further reacted for 2 hours. At last, 2-bromothiophene $(0.05 \mathrm{~mL})$ was added to end up the reaction. After cooling to room temperature, the mixture was precipitated into methanol. The crude polymer was obtained after filtration. Then the polymer was purified by Soxhlet extraction with methanol, acetone, hexane and chloroform. (121 mg, 40.2\%) ${ }^{1} \mathrm{H}$ NMR (400 MHz, $\left.\mathrm{CDCl}_{3}, \delta\right)$ : 8.60 (br, 2H), 7.99 (br, 2H), 7.80 (br, 2H), 7.59 (br, 2H), 7.41-7.37 (m, 4H), 4.26 (br, 4H), $4.37(\mathrm{br}, 4 \mathrm{H}), 2.14-2.06(\mathrm{~m}, 6 \mathrm{H}), 1.64-1.25(\mathrm{~m}, 96 \mathrm{H}), 0.97(\mathrm{br}, 6 \mathrm{H}), 0.86(\mathrm{br}, 12 \mathrm{H}) . M_{\mathrm{n}}=14.9$ $\mathrm{kDa}$, polydispersity $(\mathrm{PDI})=1.4$

\subsubsection{PNT2FTBT}

PNT2FTBT was obtained with the same method as PNDTBT. (186 mg, 70.1\%). ${ }^{1} \mathrm{H}$ NMR (400 MHz, $\left.\mathrm{CDCl}_{3}, \delta\right): 8.40-7.60$ (br, 12H), 3.56 (br, 4H), 2.18 (br, 2H), 1.64-1.31 (m, 80H), $0.90(\mathrm{~m}, 12 \mathrm{H}) . M_{n}=15.7 \mathrm{kDa}, \mathrm{PDI}=3.2$.

\subsubsection{PN2FTBT}

M1 (0.198 g, $0.2 \mathrm{mmol})$, M4 (0.132 g, $0.2 \mathrm{mmol})$, tris(dibenzlideneacet-one)dipalladium (7 $\mathrm{mg}, 0.008 \mathrm{mmol})$, tri(o-tolyl)phosphine $(5 \mathrm{mg}, 0.016 \mathrm{mmol})$ and $1 \mathrm{~mL}$ of chlorobenzene were added into a $5 \mathrm{~mL}$ microwave vial. Then the mixture was heated at $80{ }^{\circ} \mathrm{C}(10 \mathrm{~min}), 100{ }^{\circ} \mathrm{C}$ $(10 \mathrm{~min})$ and $140{ }^{\circ} \mathrm{C}(40 \mathrm{~min})$ in a microwave reactor. Tributyl(thiophen-2-yl)stannane $(0.05$ g) was added and the mixture was further reacted at $140{ }^{\circ} \mathrm{C}$ for $20 \mathrm{~min}$. The solution was cooled down to room temperature and 2-bromothiophene $(0.02 \mathrm{~g})$ was added. Then the solution was heated at $140{ }^{\circ} \mathrm{C}$ for another $20 \mathrm{~min}$. After cooling to room temperature, the mixture was precipitated into methanol. The crude polymer was obtained after filtration. Then the polymer was purified by Soxhlet extraction with methanol, acetone, hexane and chloroform. (87 mg, 37.3\%). ${ }^{1} \mathrm{H}$ NMR (400 MHz, $\mathrm{CDCl}_{3}, \delta$ ): 8.23 (br, 2H), 7.71-7.66 (m, 6H), $3.82(\mathrm{br}, 4 \mathrm{H}), 2.25(\mathrm{br}, 4 \mathrm{H}), 1.68-1.33(\mathrm{~m}, 80 \mathrm{H}), 0.90(\mathrm{~m}, 12 \mathrm{H}) . M_{\mathrm{n}}=16.9 \mathrm{kDa}, \mathrm{PDI}=1.71$. 


\subsection{Instruments and measurements}

${ }^{1} \mathrm{H}$ NMR and ${ }^{13} \mathrm{C}$ NMR spectra were obtained from a Bruker AVANCE-400 spectrometer with tetramethylsilane (TMS) as the internal reference. Molecular weights and polydispersity indices (PDIs) of the polymers were measured with the Gel permeation chromatography (GPC) method in THF on a Waters 1515 system. Absorption spectrum was investigated on a Perkin-Elmer Lamada 35 ultraviolet-visible (UV-Vis) spectrophotometer. The polymer films were spin-coated onto glass slides from a $6 \mathrm{mg} / \mathrm{mL}$ polymer solution in chlorobenzene. Thermogravimetric analysis was carried out on a Netzsch STA 449C instrument with a heating rate of $15 \mathrm{~K} / \mathrm{min}$ under nitrogen atmosphere.

\subsection{Electrochemistry}

Cyclic voltammetry (CV) measurements were carried out with a CHI660E potentiostat/galvanostat electrochemical workstation with a scan rate of $50 \mathrm{mV} / \mathrm{s}$. Pt disk coated with the polymer film was used as working electrode, while Pt wire was used as a counter electrode, and $\mathrm{Ag} / \mathrm{Ag}^{+}\left(0.01 \mathrm{M} \mathrm{AgNO}_{3}\right.$ in anhydrous acetonitrile) was used as a reference electrode in anhydrous nitrogen-saturated acetonitrile solution of $0.1 \mathrm{M}$ tetrabutylammonium hexafluorophosphate $\left(\mathrm{Bu}_{4} \mathrm{NPF}_{6}\right)$. Polymer thin film was deposited onto the working electrode from a $2 \mathrm{mg} / \mathrm{mL}$ chloroform solution. The energy level of $\mathrm{Ag} / \mathrm{Ag}^{+}$ reference electrode was calibrated against $\mathrm{Fe} / \mathrm{Fe}^{+}$to be $-4.82 \mathrm{eV}$. The HOMO and LUMO energy levels were calculated according to the following equations:

$E_{\text {Hомо }}=-\left(E_{\text {ox }}+4.82\right)(\mathrm{eV})$

$E_{\mathrm{LUMO}}=-\left(E_{\mathrm{red}}+4.82\right)(\mathrm{eV})$

Where $E_{\text {ox }}$ is the onset oxidation potentials versus $\mathrm{Ag} / \mathrm{Ag}^{+}$and $E_{\text {red }}$ is the onset reduction potentials, respectively.

\subsection{Fabrication and characterization of PSCs}

PSCs were fabricated with the structure of ITO/PEDOT:PSS/polymer:PC ${ }_{71} \mathrm{BM} / \mathrm{PIFB} / \mathrm{Al}$. Indium-tin oxide (ITO) coated glass substrates $(15 \Omega /$ sq) were ultrasonically cleaned with detergent, deionized water, acetone and isopropanol for $30 \mathrm{~min}$ each, then dried overnight in an oven at $130{ }^{\circ} \mathrm{C}$ overnight, then subjected to $\mathrm{UV}_{-} \mathrm{O}_{3}$ treatment for $15 \mathrm{~min}$. 
Poly(3,4-ethylenedioxythiophene):poly(styrenesulfonate) (PEDOT:PSS) was filtered through a $0.45 \mu \mathrm{m}$ filter before being deposited onto the ITO glass at $3000 \mathrm{rpm}$ for $30 \mathrm{~s}$, then the film-loaded substrate was baked at $140{ }^{\circ} \mathrm{C}$ for $10 \mathrm{~min}$ in air. A mixture of polymer and $\mathrm{PC}_{71} \mathrm{BM}$ at different weight ratios $(20 \mathrm{mg} / \mathrm{mL}$ ) in chlorobenzene (with/without $2 \mathrm{vol} \%$ diphenyl ether (DPE)) was stirred overnight and filtered through a $0.45 \mu \mathrm{m}$ filter, then spin-casted onto the PEDOT:PSS layer at 800-2000 rpm for 60s in glove box. PIFB was prepared according to our previous report [31]. The PIFB layer $(\sim 1 \mathrm{~nm})$ was obtained by spin-coating a methanol solution $(0.3 \mathrm{mg} / \mathrm{mL})$ on the top of the active layer. Finally, a layer of aluminum cathode was deposited onto the PIFB layer through a shadow mask by thermal evaporation. Device characterization was carried out under AM 1.5 G irradiation (100 $\mathrm{mW} / \mathrm{cm}^{2}$ ) on an Oriel sol3A simulator (Newport) with a NREL-certified silicon reference cell. EQE spectra was obtained from a Newport EQE measure system. The current density-voltage $(J-V)$ curves were measured by a Keithley 2440 source measurement unit.

Hole-only devices were fabricated with the structure of ITO/PEDOT:PSS/polymer/MoO$/ \mathrm{Au}$. ITO coated glass substrates, PEDOT:PSS layer was prepared with the same method as that used for PSCs. Polymer thin film was spin-coated from a $6 \mathrm{mg} / \mathrm{mL}$ chlorobenzene solution onto the PEDOT:PSS layer. $\mathrm{MoO}_{3}$ was thermally evaporated on the polymer thin film. Finally, a layer of Au cathode was thermally evaporated. The measurement was carried out by an Agilent 4155C semiconductor parameter analyzer. The space charge limited current (SCLC) carrier mobility was calculated from current-voltage curve according to the reported method [32].

Top-contact organic field effect transistors (OFETs) were fabricated on a common gate consisting of $\mathrm{Si}$ substrate with a $300 \mathrm{~nm}$-thick $\mathrm{SiO}_{2}$ dielectrics. The substrates were ultrasonically cleaned with piranha $\left(\mathrm{H}_{2} \mathrm{SO}_{4} / \mathrm{H}_{2} \mathrm{O}_{2}=3 / 1\right)$, deionized water, acetone and isopropanol for $30 \mathrm{~min}$ each, then dried overnight in an oven, next modified with hexamethyldisilazane (HMDS) to form a self-assembled monolayer (SAM). Polymer thin film was spin-coated from a $6 \mathrm{mg} / \mathrm{mL}$ chlorobenzene solution onto the $\mathrm{Si}$ substrate to form a thin film. Gold top contact source and drain electrodes were evaporated onto the films under vacuum $\left(1 \times 10^{-4} \mathrm{~Pa}\right)$. The OFET devices had a channel width $(W)$ of $6 \mathrm{~mm}$ and a channel length $(L)$ of $0.3 \mathrm{~mm}$. The characterization of OFETs was carried out in the air using an 
Agilent 4155C semiconductor parameter analyzer with the ICS lite software. Hole mobility $\mu$, was calculated from the data in the saturated regime according to the following equation:

$\left(I_{\mathrm{d}}\right)_{\mathrm{sat}}=(W / 2 L) \mu C_{i}\left(V_{\mathrm{g}}-V_{\mathrm{th}}\right)^{2}$

Where $\left(I_{\mathrm{d}}\right)_{\text {sat }}$ is the drain current in the saturated regime, $W$ and $L$ are the semiconductor channel width and length respectively, $C_{\mathrm{i}}$ is the capacitance of the gate dielectric layer, $V_{\mathrm{g}}$ and $V_{\text {th }}$ are the gate voltage and the threshold voltage, respectively.

\section{Results and discussion}

\subsection{Synthesis of monomers and polymers}

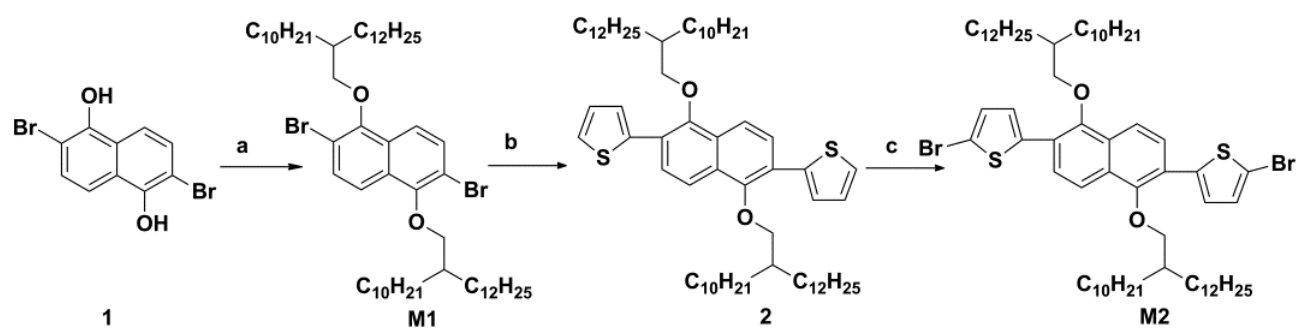

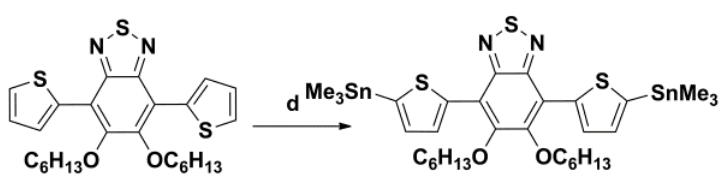

3

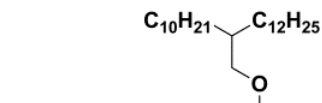

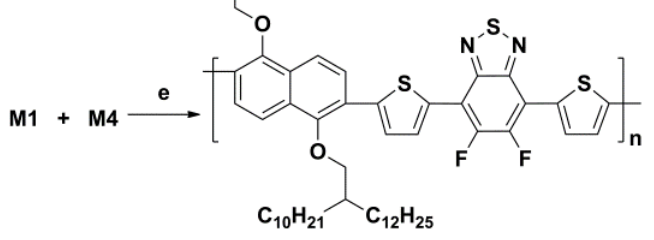

PN2FTBT

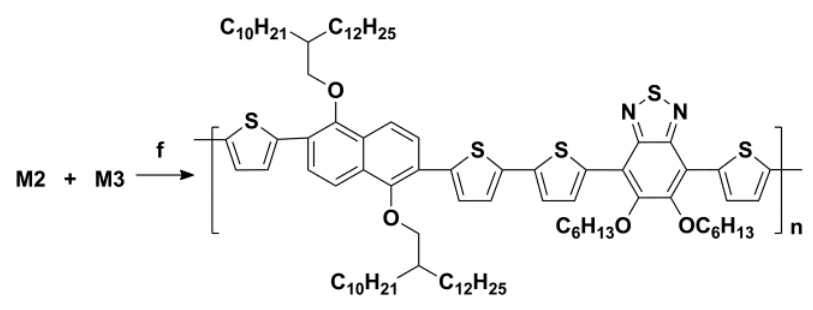

PNDTBT

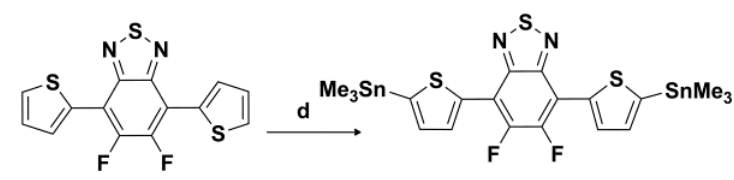

4

M4

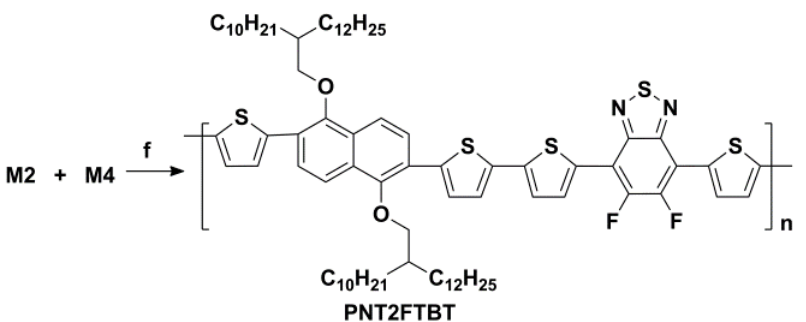

Scheme 1. Synthesis of monomers and copolymers. Reagents and reaction conditions: (a)

$\mathrm{NaOH}, \mathrm{C}_{24} \mathrm{H}_{49} \mathrm{Br}, 85^{\circ} \mathrm{C}, \mathrm{N}_{2}$, DMSO; (b) tributyl(thiophen-2-yl)stannane, $\mathrm{Pd}\left(\mathrm{PPh}_{3}\right)_{4}, \mathrm{DMF}$, toluene, $90{ }^{\circ} \mathrm{C}, \mathrm{N}_{2}$; (c) $\mathrm{HOAc}, \mathrm{CH}_{2} \mathrm{Cl}_{2}$, NBS, $0{ }^{\circ} \mathrm{C}$; (d) $n$-BuLi, $\left(\mathrm{CH}_{3}\right)_{3} \mathrm{SnCl}$, THF, $-78{ }^{\circ} \mathrm{C}$; (e) 
$\mathrm{Pd}_{2}(\mathrm{dba})_{3}, \mathrm{P}(o \text {-tol })_{3}$, chlorobenzene, microwave; (f) $\mathrm{Pd}\left(\mathrm{PPh}_{3}\right)_{4}$, toluene, reflux, $\mathrm{N}_{2}$.

The synthesis of monomers and polymers are outlined in Scheme 1. 2,6-Dibromo-1,5-bis((2-decyltetradecyl)oxy)naphthalene (M1) was prepared from commercially available 2,6-dibromonaphthalene-1,5-diol (1) via the alkylation reaction with $\mathrm{C}_{24} \mathrm{H}_{49} \mathrm{Br}$ in $55 \%$ yield. Compound $\mathbf{M 1}$ was coupled with 2-tributylstannylthiophene to afford 2,2'-(1,5-bis((2-decyltetradecyl)oxy)naphthalene-2,6-diyl)dithiophene 5,5'-(1,5-Bis((2-decyltetradecyl)oxy)naphthalene-2,6-diyl)bis(2-bromothiophene) (M2) was obtained through a bromination reaction in the presence of $\mathrm{NBS} / \mathrm{CH}_{2} \mathrm{Cl}_{2} / \mathrm{HOAc}$. PNDTBT and PNT2FTBT were prepared by a Stille coupling polymerization, using $\mathrm{Pd}\left(\mathrm{PPh}_{3}\right)_{4}$ as the catalyst in toluene. PN2FTBT could not be obtained with the same polymerization method, probably because of the large steric hindrance between M1 and M4. Nonetheless, PN2FTBT was prepared by a microwave reaction using $\mathrm{Pd}_{2}(\mathrm{dba})_{3} / \mathrm{P}(\mathrm{o} \text {-tolyl })_{3}$ as a catalyst in chlorobenzene. The structures of monomers were confirmed by ${ }^{1} \mathrm{H}$ NMR, ${ }^{13} \mathrm{C}$ NMR and High Resolution Mass Spectrometry (HRMS). All copolymers are soluble in chloroform, chlorobenzene, or $o$-dichlorobenzene. The molecular weights and polydispersity indices (PDIs) were determined by gel permeation chromatography (GPC) with monodispersed polystyrene as standard and THF as eluent. The number-average molecular weights $\left(M_{\mathrm{n}}\right)$ of PNDTBT, PNT2FTBT and PD2FTBT were measured to be 14.9, 15.4 and 16.9 KDa with PDIs of $1.40,3.20$ and 1.71 , respectively. The thermal stability of polymers were evaluated with thermogravimetric analysis (TGA) under nitrogen atmosphere, the decomposition temperature $\left(T_{\mathrm{d}}\right)$ with $5 \%$ weight loss was measured to be $336{ }^{\circ} \mathrm{C}, 341{ }^{\circ} \mathrm{C}, 372{ }^{\circ} \mathrm{C}$ for PNDTBT, PNT2FTBT and PN2FTBT respectively (Fig. S1). The TGA results show that these copolymers are quite thermally stable in $\mathrm{N}_{2}$.

\subsection{Optical and electrochemical properties}

The optical properties of the three copolymers were investigated by UV-vis absorption spectroscopy. The absorption spectra for PNDTBT, PNT2FTBT and PN2FTBT in chlorobenzene $(\mathrm{CB})$ solution and thin film are showed in Fig. 1 and relevant data are collected in Table 1. Obviously, there are two main absorption bands for each copolymer. The 
shorter wavelength bands are attributed to the $\pi-\pi^{*}$ transition of the donor units, and the longer absorption bands come from the intramolecular charge transfer (ICT) between donor and acceptor units. All the three copolymers show similar absorption shapes because they share a similar conjugation skeleton. PN2FTBT has two less thiophene rings in every repeat unit, therefore an expected blue shift in absorption was observed in comparison with PNT2FTBT. In the long wavelength regions, absorption peaks of the polymers locate at 532 $\mathrm{nm}, 580 \mathrm{~nm}$ and $547 \mathrm{~nm}$ for PNDTBT, PNT2FTBT and PN2FTBT in solution, and $565 \mathrm{~nm}$, $614 \mathrm{~nm}, 597 \mathrm{~nm}$ in thin film, respectively. PNT2FTBT and PN2FTBT exhibit red-shifted absorption maxima compared to PNDTBT, indicating a stronger charge transfer caused by introduction of the strong electron-withdrawing substituent (F) [33]. For the three copolymers, PNDTBT and PNT2FTBT exhibit a similar absorption red shift of 33 34 nm in going from the solution to the thin film because they share the same polymer backbone. However, PN2FTBT exhibits a larger absorption red shift of $50 \mathrm{~nm}$ in going from the solution to the thin film. This can be attributed to the less thiophene groups for the PN2FTBT compared to PNT2FTBT. Subsequently, the polymer backbone of PN2FTBT is less planar in the solution state, whereas in the solid state it becomes coplanar induced by the interchain stacking which leads to a bathochromically shifted absorption. With two more thiophene rings for PNDTBT and PNT2FTBT, their polymer backbones become more planar in the solution state, and thus less red-shifted absorption maxima in going from the solution to the thin film are observed.

Cyclic voltammetry measurements were performed to investigate the energy levels of these polymers and the results are shown in Fig. 2. For PNBTBT, the onset oxidation potential $\left(\varphi_{\mathrm{ox}}\right)$ is $0.62 \mathrm{~V}$, corresponding to a HOMO energy level of $-5.44 \mathrm{eV}$. Because of the strong electron-withdrawing ability of fluorine atoms, the oxidation potential of PNT2FTBT was found to be $0.08 \mathrm{eV}$ larger than that of PNDTBT, which corresponds to a deeper HOMO level of $-5.52 \mathrm{eV}$. Similarly, PN2FTBT has a large oxidation potential of $0.79 \mathrm{eV}$ and a deep HOMO of $-5.61 \mathrm{eV}$. All the polymers showed well-defined oxidation peaks, however, the reduction peaks were rather weak and are not shown in the Figure. Whereas, the LUMO energy levels of these copolymers were calculated from the optical bandgaps and their HOMO energy levels. For PNDTBT, the LUMO energy level is $-3.58 \mathrm{eV}$, yielding an enough LUMO offset with $\mathrm{PC}_{71} \mathrm{BM}$ to ensure efficient exciton dissociation (Fig. 2). However, for 
PNT2FTBT and PN2FTBT, the LUMO energy levels were calculated to be $-3.79 \mathrm{eV}$ and $-3.80 \mathrm{eV}$, close to the LUMO energy level of $\mathrm{PC}_{71} \mathrm{BM}$ which may lead to some loss in open circuit voltages $[11,34]$.
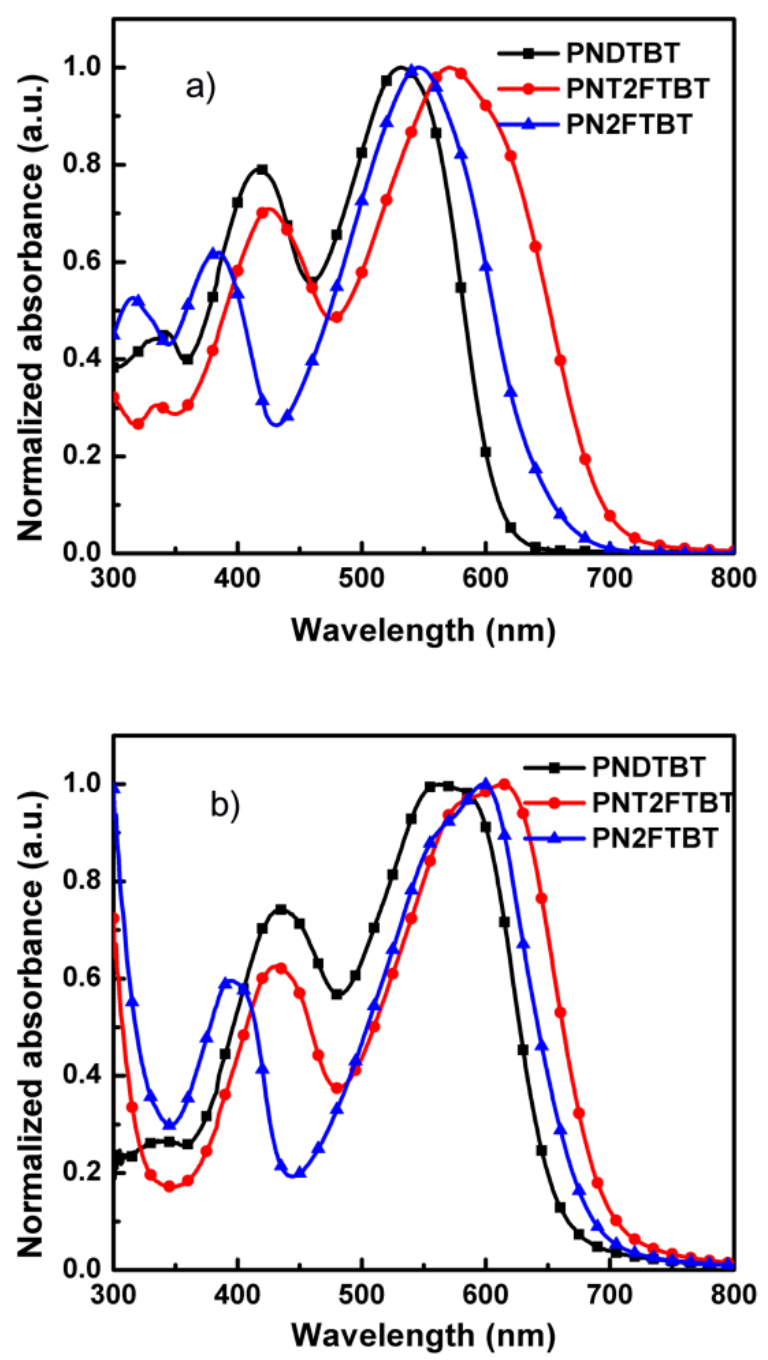

Fig. 1 Normalized UV-vis absorption spectra of the copolymers (a) in dilute chlorobenzene solution $\left(1 \times 10^{-5} \mathrm{M}\right)$ and $(\mathrm{b})$ in solid thin film. 

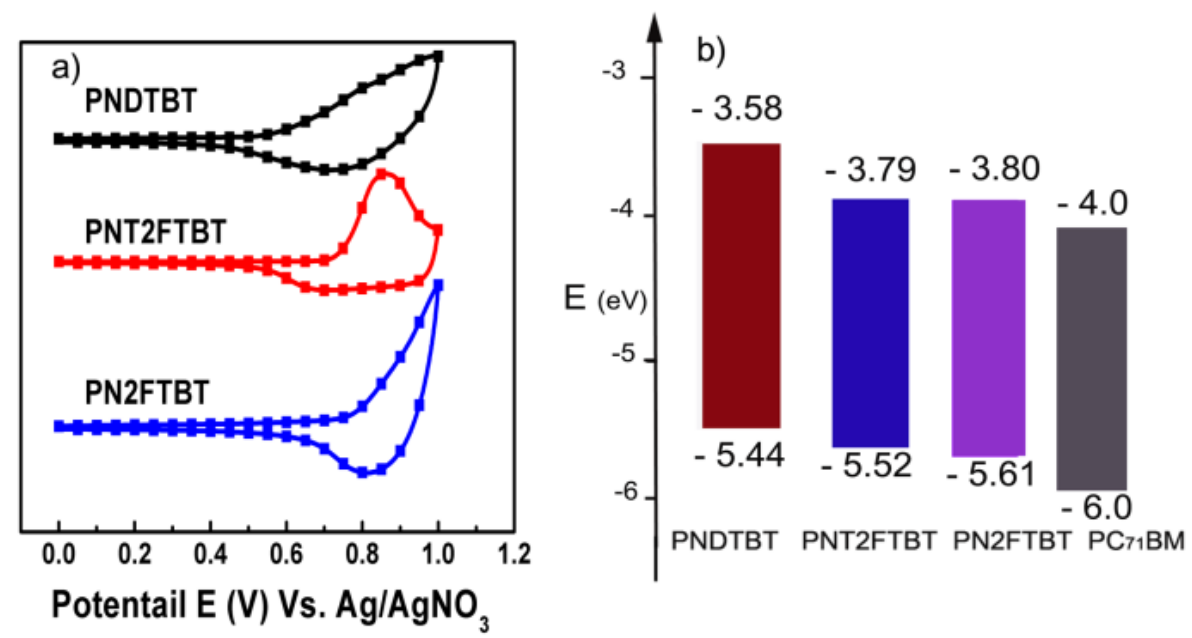

Fig. 2 (a) Cyclic voltammograms (positive part) of polymer thin films on Pt electrode in 0.1 $\mathrm{M} \mathrm{Bu}_{4} \mathrm{NPF}_{6}$ acetonitrile solution at $50 \mathrm{mV} / \mathrm{min}$. (b) energy level diagrams for the polymers and $\mathrm{PC}_{71} \mathrm{BM}$.

\subsection{Hole mobility}

Top-contact/bottom-gate OFETs based on PNDTBT, PNT2FTBT and PN2FTBT were fabricated under ambient conditions by spin-casting chlorobenzene solutions of the synthesized polymers on the heavily doped Si (100) substrates treated with HMDS. The transfer curves of the polymer-based OFETs are shown in Fig. 3a-c. The saturation region mobilities were calculated from the transfer characteristics of the OFETs using the slope derived from the square root of the absolute value of the current as a function of gate voltage between -80 and -40 V. From Fig. 3a-c, the hole mobilities were calculated to be $5.36 \times 10^{-4}$, $1.30 \times 10^{-2}$ and $1.24 \times 10^{-2} \mathrm{~cm}^{2} \mathrm{~V}^{-1} \mathrm{~s}^{-1}$, while the on/off radios were calculated to be 27,470 , 1100 for PNDTBT, PNT2FTBT and PN2FTBT, respectively. It is obvious that the copolymers containing fluorinated units, PNT2FTBT and PN2FTBT, exhibit higher hole mobilities (OFET) and larger on/off ratios. It can be attributed to the two bulky alkoxyl group on the BT backbone of PNDTBT, which may increase the steric hindrance for the intermolecular packing, thus resulting in a decrease in mobility [35, 36]. However, for the BHJ solar cell application, the hole transporting property in the vertical direction is responsible for the photovoltaic performance of devices. Therefore, we also fabricated hole-only devices with the structure of ITO/PEDOT:PSS/polymer/ $/ \mathrm{MoO}_{3} / \mathrm{Au}$ in order to investigate the hole mobility of the polymers by the SCLC method. The $J^{0.5} \sim V$ characteristics 
of hole-only devices based on the three different polymers are shown in Fig. 3d. Hole mobilities were calculated to be $1.81 \times 10^{-4}, 7.01 \times 10^{-5}$ and $4.03 \times 10^{-5} \mathrm{~cm}^{2} \mathrm{~V}^{-1} \mathrm{~s}^{-1}$ for thin films of PNDTBT, PNT2FTBT and PN2FTBT, respectively. Interestingly, it is found that with the SCLC method, copolymers with dialkoxyl substituted BT (PNDTBT) exhibit a higher mobility of $1.81 \times 10^{-4} \mathrm{~cm}^{2} \mathrm{~V}^{-1} \mathrm{~s}^{-1}$ in comparison with PNT2FTBT $\left(7.01 \times 10^{-5} \mathrm{~cm}^{2} \mathrm{~V}^{-1} \mathrm{~s}^{-1}\right)$. The higher hole mobility of PNDTBT will provide an advantage in the solar cell application compared to PNT2FTBT, which will be discussed in the next section. It should be noted that all the three polymers are amorphous according to the XRD analysis of the pristine thin films (Fig. S2).
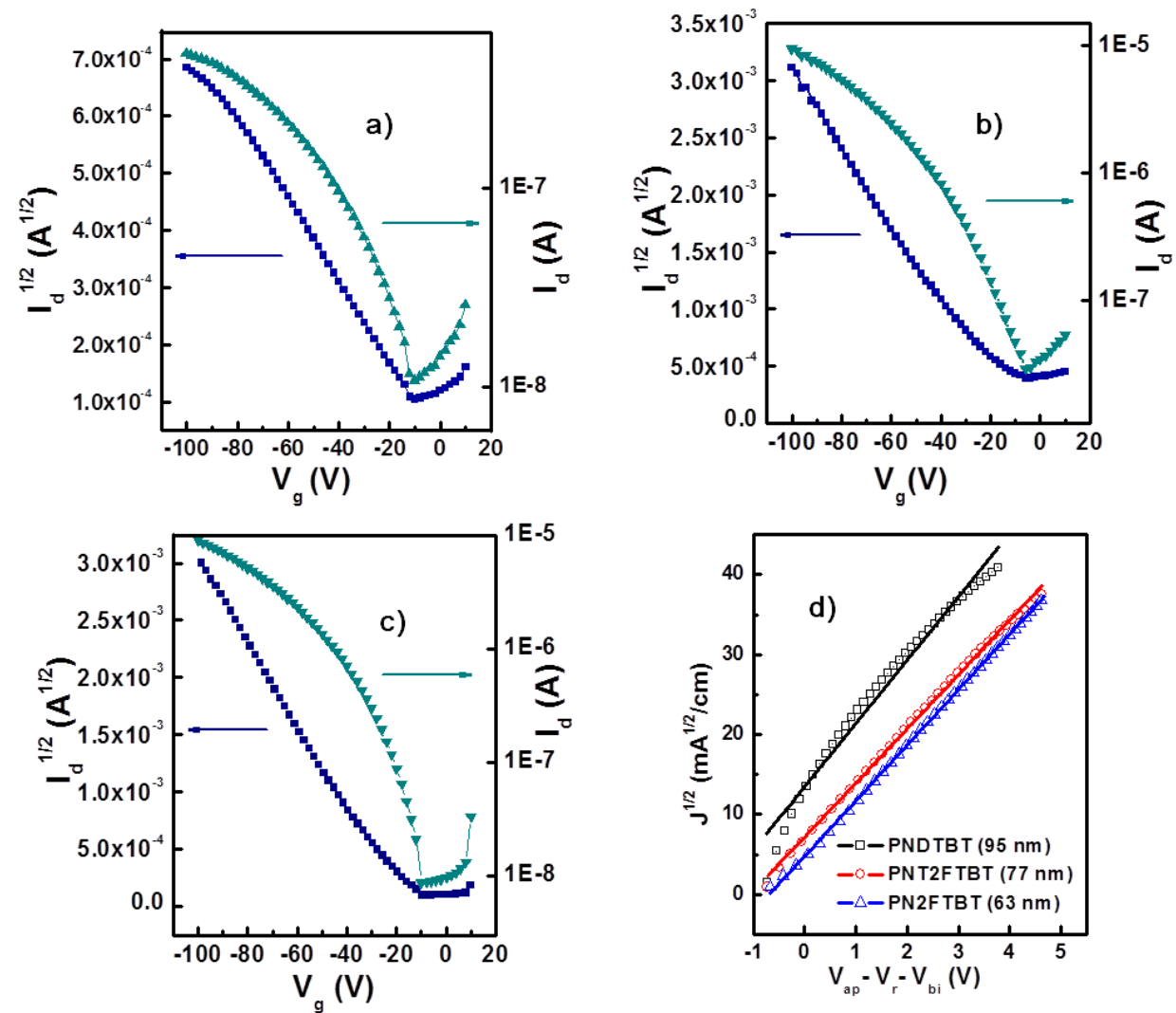

Fig. 3 Typical transfer curves of OFETs for (a) PNDTBT, (b) PNT2FTBT, (c) PN2FTBT, and (d) $J^{0.5} \sim V$ characteristics (SCLC) of hole-only devices based on the three polymers. 
Table 1 Summary of molecular weights, thermal stability, optical and electrochemical properties of the polymers.

\begin{tabular}{ccccccccc}
\hline Polymers & $\begin{array}{c}M_{\mathrm{n}} \\
(\mathrm{kg} / \mathrm{mol})^{\mathrm{a}}\end{array}$ & PDI & $\begin{array}{c}\lambda_{\max } \text { in } \\
\text { chloroform } \\
(\mathrm{nm})\end{array}$ & $\begin{array}{c}\lambda_{\max } \text { in } \\
\text { film }(\mathrm{nm})\end{array}$ & $\begin{array}{c}E_{\mathrm{g}} \mathrm{opt}^{\mathrm{b}} \\
(\mathrm{eV})^{\mathrm{b}}\end{array}$ & $\begin{array}{c}\mathrm{HOMO} \\
(\mathrm{eV})^{\mathrm{c}}\end{array}$ & $\begin{array}{c}\text { LUMO } \\
(\mathrm{eV})^{\mathrm{d}}\end{array}$ & $\begin{array}{c}\mathrm{T}_{\mathrm{d}} \\
\left({ }^{\circ} \mathrm{C}\right)^{\mathrm{e}}\end{array}$ \\
\hline PNDTBT & 14.9 & 1.40 & 532 & 565 & 1.86 & -5.44 & -3.58 & 336 \\
PNT2FTBT & 15.4 & 3.20 & 580 & 614 & 1.73 & -5.52 & -3.79 & 341 \\
PN2FTBT & 16.9 & 1.71 & 547 & 597 & 1.77 & -5.61 & -3.80 & 372 \\
\hline
\end{tabular}

${ }^{\mathrm{a}}$ The number-average molecular weight $\left(M_{\mathrm{n}}\right)$ and polydispersity index (PDI) were measured by GPC. ${ }^{\mathrm{b}} \lambda_{\max }$ were measured by UV-Vis spectrophotometer, the optical bandgaps were calculated from the onset of the thin film absorption spectra. ${ }^{c}$ calculated from the onset of CV curve in thin film. ${ }^{d}$ calculated from the optical bandgap and the HOMO energy level. ${ }^{\mathrm{e}}$ measured by thermogravimetric analysis.

Table 2 Device parameters of PSCs based on the copolymers, and hole mobilities of the copolymers.

\begin{tabular}{cccccccc}
\hline Polymers & $V_{o c}(\mathrm{~V})$ & $\begin{array}{c}J_{s c} \\
\left(\mathrm{~mA} / \mathrm{cm}^{2}\right)\end{array}$ & $\mathrm{FF}(\%)$ & $\begin{array}{c}\mathrm{PCE}_{\text {ave }}{ }^{\mathrm{a}} \\
(\%)\end{array}$ & $\begin{array}{c}\mathrm{PCE}_{\max } \\
(\%)\end{array}$ & $\begin{array}{c}\mu_{\text {hole }} \text { OFET } \\
\left(\mathrm{cm}^{2} \mathrm{~V}^{-1} \mathrm{~s}^{-1}\right)\end{array}$ & $\begin{array}{c}\mu_{\text {hole }} \text { SCLC } \\
\left(\mathrm{cm}^{2} \mathrm{~V}^{-1} \mathrm{~s}^{-1}\right)\end{array}$ \\
\hline PNDTBT & 0.94 & 10.76 & 61.84 & $5.85 \pm 0.16$ & 6.24 & $5.36 \times 10^{-4}$ & $1.81 \times 10^{-4}$ \\
PNT2FTBT & 0.82 & 9.62 & 64.25 & $4.91 \pm 0.08$ & 5.09 & $1.30 \times 10^{-2}$ & $7.01 \times 10^{-5}$ \\
PN2FTBT & 0.78 & 4.88 & 52.03 & $1.92 \pm 0.06$ & 1.97 & $1.24 \times 10^{-2}$ & $4.03 \times 10^{-5}$ \\
\hline
\end{tabular}

${ }^{a}$ The average PCE is obtained from eight devices.

\subsection{Photovoltaic performance}



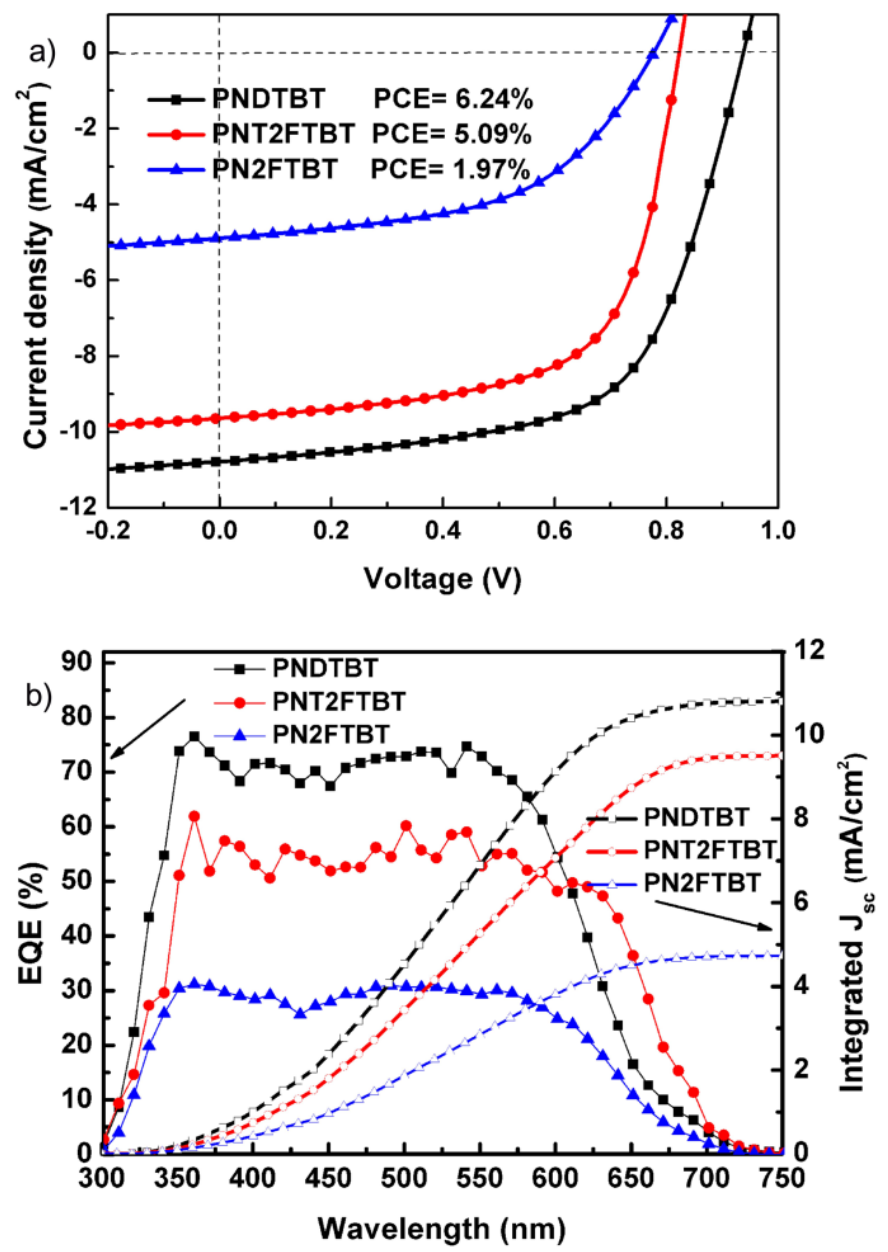

Fig. 4 (a) Current density $(J)$-voltage $(V)$ characteristics of PSCs based on PNDTBT, PNT2FTBT and PN2FTBT. (b) Corresponding EQE spectra (solid lines) of the PSCs and their integrated photocurrents (hollow lines).

PSC devices were fabricated with the conventional structure of ITO/PEDOT:PSS/polymer:PC ${ }_{71} \mathrm{BM} / \mathrm{PIFB} / \mathrm{Al}$. Chlorobenzene (with/without DPE) was used as the processing solvent because of its good solvation properties, low evaporation rates and good film forming ability. Donor/acceptor ratio, spinning rates and spinning time were carefully optimized for high performance solar cells. The best PSCs were fabricated with a D/A ratio of 1:1.5 (w/w), and a spinning rate of $1000 \mathrm{rpm}$. The device parameters are summarized in Table 2. Devices based on PNDTBT exhibited the best photovoltaic performance with a $J_{\mathrm{sc}}$ of $10.76 \mathrm{~mA} / \mathrm{cm}^{2}$, a $V_{\mathrm{oc}}$ of $0.94 \mathrm{~V}$, an FF of $61.84 \%$, and a PCE of 
6.24\%. External quantum efficiencies (EQEs) of the device are above $70 \%$ in the range of $350 \sim 560 \mathrm{~nm}$ with a maximum EQE of $76.7 \%$ at $360 \mathrm{~nm}$. The $J_{\mathrm{sc}}$ value calculated from the corresponding EQE spectrum is $10.80 \mathrm{~mA} / \mathrm{cm}^{2}$, in well agreement with the value obtained from the experiment measurement $(0.4 \%$ error). The efficiency of $6.24 \%$ is much higher than those of other reported dialkoxynaphthalene-based copolymers [21-24]. Furthermore, the $V_{\text {oc }}$ of $0.94 \mathrm{~V}$ is also among the the highest values reported for dialkoxynaphthalene-based copolymers. To investigate the influence of side chain, Fluorine substituted BT units were synthesized and polymerized with dialkoxynaphthalene units to afford PNT2FTBT. When the devices based on PNT2FTBT were fabricated under the same condition as those based on PNDTBT, a low efficiency of 3.15\% was achieved (Table S1). However, when 2\% DPE was used an additive in chorobenzene, an improved efficiency of 5.09\% was achieved together with a $J_{\mathrm{sc}}$ of $9.62 \mathrm{~mA} \mathrm{~cm}$, a $V_{\mathrm{oc}}$ of $0.82 \mathrm{~V}$, an FF of $64.25 \%$. This improved performance induced by the DPE additive has been found by others in some fluorizated benzthiadiazole-based copolymers [19, 37, 38]. For PN2FTBT, the devices with DPE as an additive also exhibit an increased PCE of $1.97 \%$ in comparison with those without DPE (1.22\%, Table S1). The fluorine substituent has great influence on intermolecular and intramolecular interactions, noncovalent F $\cdots \mathrm{S}$ interactions between fluorine substituents, and the thiophene rings promote the molecular planarity and arrangement in solid film, which are beneficial for light harvest and carrier transportation. As a result, the fill factor (FF) increases slightly as expected. However, the devices based on PNT2FTBT exhibit a lower PCE compared to those based on PNDTBT mainly due to the decreased $V_{\text {oc }}$ of $0.82 \mathrm{~V}$, which is $0.12 \mathrm{~V}$ lower than that of the devices based on PNDTBT. Even though PNT2FTBT has a deeper HOMO energy level, its lower LUMO energy level makes the energy gap between the LUMO of the polymer and the LUMO of $\mathrm{PC}_{71} \mathrm{BM}$ become too small to dissociate excitons. Thus a loss in the $V_{\text {oc }}$ was observed for PNT2FTBT. At the same time, the increased PCE for PNDTBT can be also attributed to its higher hole mobility (SCLC), which help to increase the $J_{\mathrm{sc}}$ of the resulting solar cell devices. The decreased $J_{\mathrm{sc}}$ of the devices based on PNT2FTBT is evidenced by the lower EQEs in the whole photon response spectrum range (Fig. 4b). For PNT2FTBT, the integrated $J_{\mathrm{sc}}$ calculated from the EQE spectrum is 9.51 $\mathrm{mA} / \mathrm{cm}^{2}$, also in agreement with the experiment measurement (1.2\% error). The comparisons 
between copolymers PNT2FTBT and PN2FTBT show that the incorporation of two additional thiophene rings into the polymer backbone leads to an enhanced PCE (5.09\% versus 1.97\%). The devices based on PN2FTBT show a low PCE mainly due to the decreased $J_{\mathrm{sc}}, V_{\mathrm{oc}}$, and FF. From the EQE curve in Fig. $4 \mathrm{~b}$, one may find that the photon response range of the devices based on PN2FTBT is the same as those based on PNT2FTBT except the relatively low $\mathrm{EQE}$ values for the former. The photovoltaic performance comparison between copolymers PNT2FTBT and PN2FTBT suggests that the planarity of polymer backbone is important measure to achieve high performance solar cells in addition to the considerations on the band-gaps and energy levels of copolymers.

\subsection{Morphology}

The morphology of active layers plays a critical role on the photovoltaic performance of the corresponding devices. In this work, the morphology of the surface of the active layers was studied by tapping mode atomic force microscopy (AFM). The active layer films were prepared using the same conditions as those used for the optimized devices. The topographic images and the corresponding phase images were shown in Fig 5. The images of the three blended films showed uniformly percolated structures and smooth surfaces with root-mean-square (rms) roughness values of 2.37, 0.89 and $0.97 \mathrm{~nm}$ for PNDTBT, PNT2FTBT, and PN2FTBT, respectively. At the same time, small phase separation domains were found for the blended films. In particular, the blended film based on PNDTBT:PC ${ }_{71} \mathrm{BM}$ showed much the most clear phase separation with an optimal domain size of 15 20 nm, which is beneficial for the efficient exciton diffusion to the donor-acceptor interface and the enhancement of the resulting device performance $\left(J_{\mathrm{sc}}=10.76 \mathrm{~mA} / \mathrm{cm}^{2}, \mathrm{FF}=61.84 \%, \mathrm{PCE}=\right.$ 6.24\%). Nonetheless, the films based on PNT2FTBT:PC ${ }_{71} \mathrm{BM}$ and PN2FTBT:PC $\mathrm{P}_{71} \mathrm{BM}$ displayed more smooth surface in comparison with that based on PNDTBT:PC ${ }_{71} \mathrm{BM}$, which can be attributed to the incorporation of the diphenyl ether additive. Further work regarding the morphology influence of the additive on the active layers is underway. 

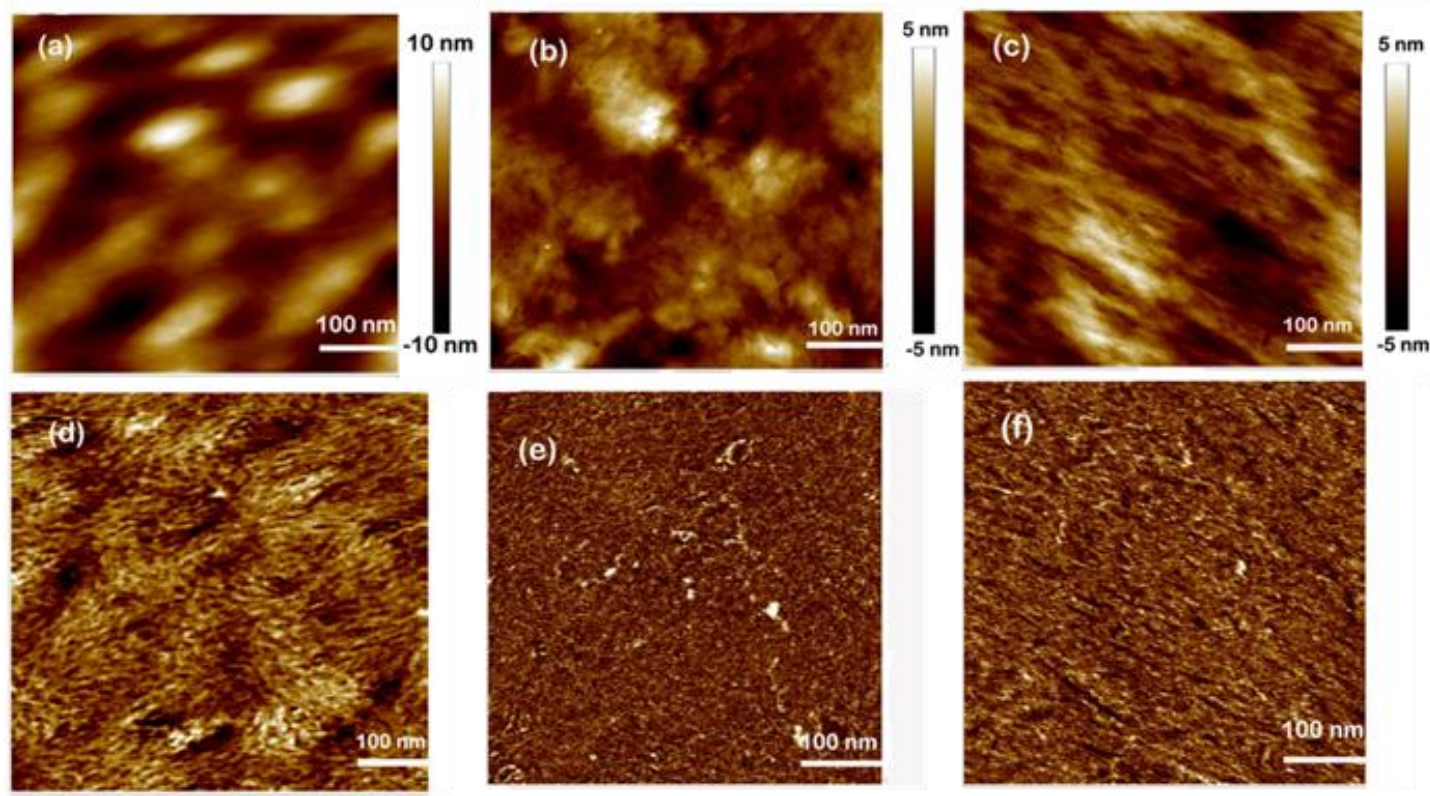

Fig. 5 AFM topographic images (top) and the corresponding phase images (bottom) of the surface of (a, d) PNDTBT:PC ${ }_{71} \mathrm{BM},(b, \mathrm{e})$ PNT2FTBT:PC ${ }_{71} \mathrm{BM}$ and (c, f) PN2FTBT:PC ${ }_{71} \mathrm{BM}$ under the optimized condition.

\section{Conclusions}

In summary, three dialkoxynaphthalene-based conjugated polymers, PNDTBT, PNT2FTBT and PN2FTBT, were designed, synthesized and characterized for polymer solar cells. Hole transporting properties of the synthesized copolymers were investigated by using the SCLC and OFET methods. All the three copolymers have deep-lying HOMO energy levels with band gaps ranged from 1.73 to $1.86 \mathrm{eV}$. An in-depth study of the substitutes on the benzothiadiazole has been carried out. The inclusion of the fluorine atoms in the polymer backbone leads to a decrease in the HOMO energy level, whereas the inclusion of the alkoxyl groups leads to an increase in the HOMO energy level. With the OFET method, copolymers based on dialkoxyl substituted BT (PNDTBT) exhibit a hole mobility of $5.36 \times 10^{-4} \mathrm{~cm}^{2} \mathrm{~V}^{-1} \mathrm{~s}^{-1}$, much lower than the copolymers based on the fluorinated BT (PNT2FTBT, $1.30 \times 10^{-2} \mathrm{~cm}^{2} \mathrm{~V}^{-1}$ $\left.\mathrm{s}^{-1}\right)$. However, with the SCLC method, PNDTBT exhibits a hole mobility of $1.81 \times 10^{-4} \mathrm{~cm}^{2}$ $\mathrm{V}^{-1} \mathrm{~s}^{-1}$, higher than PNT2FTBT $\left(7.01 \times 10^{-5} \mathrm{~cm}^{2} \mathrm{~V}^{-1} \mathrm{~s}^{-1}\right)$. The comparisons between copolymers PNT2FTBT and PN2FTBT show that the inclusion of two more thiophene rings 
into the polymer backbone leads to an increased hole mobility as well as the HOMO energy level. PNDTBT-based photovoltaic devices showed the highest PCE of $6.24 \%$ with a $J_{\mathrm{sc}}$ of $10.75 \mathrm{~mA} / \mathrm{cm}^{2}$, a $V_{\text {oc }}$ of $0.94 \mathrm{~V}$ and an FF of $61.84 \%$. The value is among the highest efficiency ever reported for the dialkoxynaphthalene-based copolymers. It should be noted that PNDTBT has a narrow absorption band in the short wavelength region below $660 \mathrm{~nm}$ which may make it a promising candidate for short wavelength absorbing material in tandem solar cells. PNT2FTBT-based PSCs exhibit a slightly lower PCE of 5.09\% with a $V_{\text {oc }}$ of 0.82 V in comparison with PNDTBT-based devices, which can be attributed to the lower hole mobility (SCLC) as well as the lower LUMO energy level for PNT2FBT. Compared to PNT2FTBT, PN2FTBT shows decreased photovoltaic performance due to the lower hole mobility and the unsuitable LUMO position. Nonetheless, our results indicate that dialkoxynaphthalene is an excellent electron donating unit for high performance polymer solar cells.

\section{Acknowledgment}

This work was supported by National Science Foundation of China (Nos 51173186, 61325026), the CAS/SAFEA International Partnership Program for Creative Research Teams, and the 100 Talents Programme of the Chinese Academy of Sciences (CAS).

\section{References}

[1] Gao J, Hummelen J, Wudl F and Heeger A. Science 1995; 270: 1789-90.

[2] Hoth CN, Choulis SA,Schilinsky P and Brabec CJ. Adv Mater 2007: 19, 3973-78.

[3] Cheng Y-J, Yang SH and Hsu CS. Chem Rev 2009; 109: 5868-5923.

[4 Zheng QD, Jung BJ, Sun J, and Katz HE. J. Am. Chem. Soc. 2010;132(15):5394-5404.

[5] Li G, Zhu R, Yang Y. Nat Photonics 2012;6:153-61.

[6] Li K, Li ZJ, Feng K, Xu XP, Wang LY, Peng Q. J Am Chem Soc 2013;135:13549-57.

[7] Zhang X, Lu ZH, Ye L, Zhan CL, Hou JH, Zhang SQ, et al. Adv Mater 2013;25:5791-97.

[8] You J, Dou L, Yoshimura K, Kato T, Ohya K, Moriarty T, et al. Nat commun 2013;4:1446.

[9] Cao JM, Liao QG, Du XY, Chen JH, Xiao Z, Zuo QQ, et al. Enegy Environ Sci 2013;6:3224-8.

[10] Chen J-D, Cui C, Li Y-Q, Zhou L, Ou Q-D, Li C, et al. Adv Mater 2014: DOI: 10.1002/adma.201404535. 
[11] Yusoff AB, Kim D, Kim HP, Shneider FK, da Silva WJ, Jang J. Enegy Environ Sci 2015;8:303-16.

[12] Kim JY, Lee K, Coates NE, Moses D, Nguyen TQ, Dante M, et al. Science 2007;317:222-5.

[13] Thompson BC, Fréchet JMJ. Angew Chem Int Ed 2008;47:58-77.

[14] Brunetti FG, Kumar R, Wudl F. J Mater Chem 2010;20:2934-48.

[15] Zhou Y, Kurosawa T, Ma W, Guo YK, Fang L, Vandewal K, et al. Adv Mater 2014;26:3767-72.

[16] Neef CJ, Ferraris JP. Macromolecules 2000;33:2311-4.

[17] Shaheen SE, Brabec CJ, Sariciftci NS, Padinger F, Fromherz T, Hummelen JC. Appl Phys Lett $2001 ; 78: 841-3$

[18] Alam MM, Jenekhe SA. Chem Mater 2004;16:4647-56.

[19] Nguyen TL, Choi H, Ko SJ, Uddin MA, Walker B, Yum S, et al. Enegy Environ Sci 2014;7:3040-51.

[20] Osaka I, Shimawaki M, Mori H, Doi I, Miyazaki E, Koganezawa T, et al. J Am Chem Soc 2012;134:3498-507.

[21] Chung DS, Park JW, Kim S-O, Heo K, Park CE, Ree M, et al. Chem Mater 2009;21:5499-507.

[22] Cha H, Kim HN, An TK, Kang MS, Kwon SK, Kim YH, et al. ACS Appl Mater Interfaces 2014;6:15774-82.

[23] Kim S-O, Chung DS, Cha H, Hwang MC, Park J-W, Kim Y-H, et al. Sol Energy Mater Sol Cells 2011;95:1678-85.

[24] Kwon JH, An JY, Jang H, Choi S, Chung DS, Lee MJ, et al. J Polym Sci Part A Polym Chem 2011;49:1119-28

[25] Zhou HX, Yang LQ, Stuart AC, Price SC, Liu SB, You W. Angew Chem Int Ed 2011; 50: $2995-98$.

[26] Jiang JM, Yang PA, Hsieh TH, Wei KH. Macromolecules 2011; 44: 9155-63.

[27] Lee W, Kim GH, Ko SJ, Yum S, Hwang S, Cho S, Shin YH, Kim JY, Woo HY. Macromolecules 2014; 47: 1604-12.

[28] Jiang JM, Raghunath P, Lin HK, Lin YC, Lin MC, Wei KH, Macromolecules 2014; 47: 7070-80.

[29] Carle JE, Andreasen JW, Jorgensen M, Krebs FC. Sol Energy Mater Sol Cells 2010;94:774-80.

[30] Wang LX, Cai DD, Yin ZG, Tang CQ, Chen SC, Zheng QD. Polym Chem 2014;5:6847-56.

[31] Ma YL, Zheng QD, Yin ZG, Cai DD, Chen SC, Tang CQ. Macromolecules 2013;46:4813-21.

[32] Ma YL, Zheng QD, Wang LX, Cai DD, Tang CQ, Wang M, et al. J Mater Chem A 2014;2:13905-15.

[33] Zhang MJ, Guo X, Zhang SQ, Hou JH. Adv Mater 2014;26:1118-23. 
[34] Chen C-C, Chang WH, Yoshimura K, Ohya K, You JB, Gao J, et al. Adv Mater 2014;26:5670-77.

[35] Coropceanu V, Cornil J, da Silva DA, Olivier Y, Silbey R, Bredas JL. Chem Rev 2007;107:926-52.

[36] Deng YF, Liu J, Wang JT, Liu LH, Li WL, Tian HK, et al. Adv Mater 2014;26:471-6.

[37] Kim J, Yun MH, Kim GH, Lee J, Lee SM, Ko SJ, et al. ACS Appl Mater Interfaces 2014;6:7523-34.

[38] Kim Y, Yeom HR, Kim JY, Yang C. Enegy Environ Sci 2013;6:1909-16. 


\section{Scheme and figure captions}

Scheme 1. Synthesis of monomers and copolymers. Reagents and reaction conditions: (a) $\mathrm{NaOH}, \mathrm{C}_{24} \mathrm{H}_{49} \mathrm{Br}, 85^{\circ} \mathrm{C}, \mathrm{N}_{2}$, DMSO; (b) tributyl(thiophen-2-yl)stannane, $\mathrm{Pd}\left(\mathrm{PPh}_{3}\right)_{4}, \mathrm{DMF}$, toluene, $90{ }^{\circ} \mathrm{C}, \mathrm{N}_{2}$; (c) $\mathrm{HOAc}, \mathrm{CH}_{2} \mathrm{Cl}_{2}$, NBS, $0{ }^{\circ} \mathrm{C}$; (d) $n$-BuLi, $\left(\mathrm{CH}_{3}\right)_{3} \mathrm{SnCl}$, THF, $-78{ }^{\circ} \mathrm{C}$; (e) $\mathrm{Pd}_{2}(\mathrm{dba})_{3}, \mathrm{P}(o \text {-tol })_{3}$, chlorobenzene, microwave; (f) $\mathrm{Pd}\left(\mathrm{PPh}_{3}\right)_{4}$, toluene, reflux, $\mathrm{N}_{2}$.

Fig. 1 Normalized UV-vis absorption spectra of the copolymers (a) in dilute chlorobenzene solution $\left(1 \times 10^{-5} \mathrm{M}\right)$ and $(\mathrm{b})$ in solid thin film.

Fig. 2 (a) Cyclic voltammograms (positive part) of polymer thin films on Pt electrode in 0.1 $\mathrm{M} \mathrm{Bu}_{4} \mathrm{NPF}_{6}$ acetonitrile solution at $50 \mathrm{mV} / \mathrm{min}$. (b) energy level diagrams for the polymers and $\mathrm{PC}_{71} \mathrm{BM}$.

Fig. 3 Typical transfer curves of OFETs for (a) PNDTBT, (b) PNT2FTBT, (c) PN2FTBT, and (d) $J^{0.5} \sim V$ characteristics (SCLC) of hole-only devices based on the three polymers.

Fig. 4 (a) Current density $(J)$-voltage $(V)$ characteristics of PSCs based on PNDTBT, PNT2FTBT and PN2FTBT. (b) Corresponding EQE spectra (solid lines) of the PSCs and their integrated photocurrents (hollow lines).

Fig. 5 AFM topographic images (top) and the corresponding phase images (bottom) of the surface of (a, d) PNDTBT:PC ${ }_{71}$ BM, (b, e) PNT2FTBT:PC ${ }_{71} B M$ and (c, f) PN2FTBT:PC ${ }_{71} B M$ under the optimized condition. 


\section{GRAPHICAL ABSTRACT}

Dialkoxynaphthalene as an electron-rich unit for high-performance organic solar cells with large open circuit voltages

Hao Qin, ${ }^{\mathrm{a}, \mathrm{b}}$ Dongdong Cai, ${ }^{\mathrm{a}}$ Meng Wang, ${ }^{\mathrm{a}, \mathrm{b}}$ Yunlong Ma, ${ }^{\mathrm{a}}$ Zhigang Yin, ${ }^{\mathrm{a}, \mathrm{b}}$ Changquan Tang, ${ }^{\mathrm{a}}$ Shan-Ci Chen a and Qingdong Zheng ${ }^{\mathrm{a}, *}$

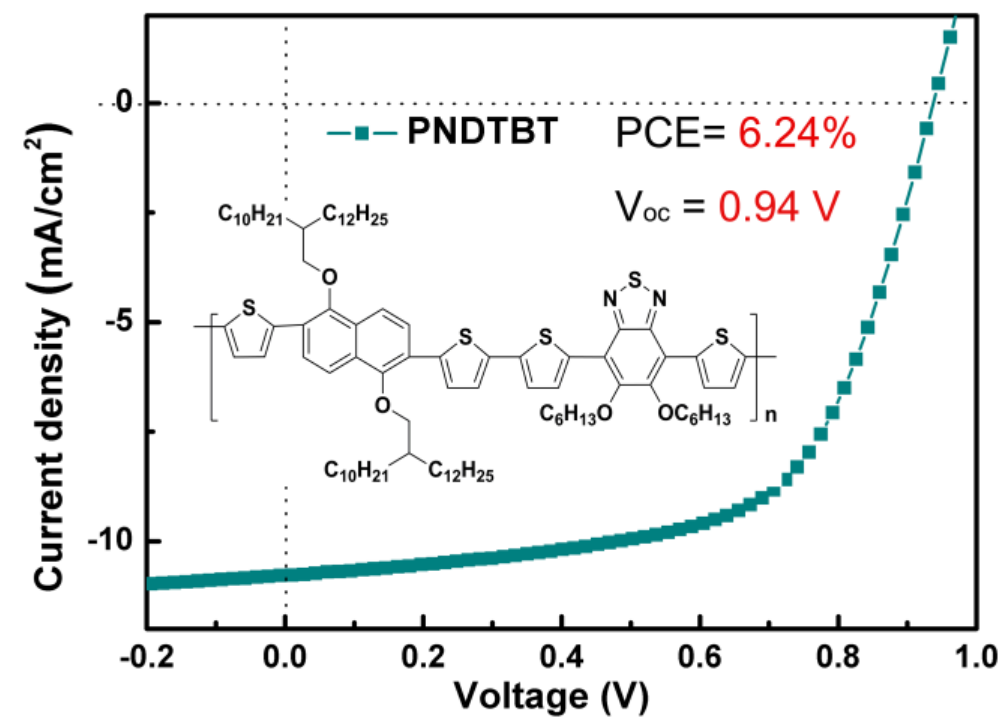

